\title{
THERMAL PERFORMANCE OF CLOSED TWO PHASE THERMOSYPHON FOR DIFFERENT CONCENTRATIONS, FILL VOLUME RATIOS AND HEAT INPUTS USING NANO-FLUIDS
}

\author{
RAMESH K RATHOD ${ }^{1}$ \& CHAVALI SHRIRAMSHASTRI ${ }^{2}$ \\ ${ }^{1}$ Department of Mechanical Engineering, Pmpri Chinchwad College of Engineering \& Research, Pune, India \\ ${ }^{2}$ Department of Mechanical Engineering, DY Patil University, Talegaon, Ambi, Pune. India
}

\section{ABSTRACT}

The continuos efforts for improving the performance of closed two phase thermosyphon (CTPT) have been put in by various researchers, since the invention of the heat pipe. This paper elaborately discusses the performance of a gravity assisted heat pipes. The experimental setup of Closed Two Phase Thermosyphon was developed with two different nanofluids, Al2O3/water and water for different concentrations of $0.1 \%, 0.3 \%$ and $0.5 \%$ and the fill volume ratios used in CTPT were $10 \%, 20 \%$ and $30 \%$ respectively. The températures range of nanofluid was varied between $300 \mathrm{C}$ to $950 \mathrm{C}$. Nanofluids used. It was found that the thermal conductivity of the nanofluid increases continuously for higher temperatures and concentrations of nanoparticles, although the rise is non-linear and declines for higher values.

KEYWORDS: Closed Two Phase Thermosyphon, Heat Transfer Coefficient, Fill Volume Ratio, Nanofluid

Received: Jun 09, 2020; Accepted: Jun 29, 2020; Published: Aug 03, 2020; Paper Id.: IJMPERDJUN2020588

\section{INTRODUCTION}

Most parts of the world like Europe and Ushas instituted laws and regulations that appreciably affect the formulation of metal cutting fluids [1]. Industries using these fluids are relentlessly searching for better performing cutting fluids formulated from environmentally friendly materials. Also, most Governments, Industries and Employee Unions implement movements for a healthy and safe work environment, as well as disposal aspects influencing the global environment. These movements have already affected the formulation of cutting fluids in Europe and the US as follows: the removal of nitrite from cutting fluid composition and the replacement of diethanolamine short chained chlorinated paraffin $[1,2]$.

Closed Two Phase Thermosyphon (CTPT) is essentially another class of heat pipes without any wick also known as wickless heat pipes. CTPT are the simplest and the condensate returns from the condenser to the evaporator is due to gravity. It is capable of transferring multiple times heat for the smaller cross section area and small temperature difference, as compared to the conventional heat transferring devices using nanofluids. A Nanofluid is a fluid containing nanometer-sized particles (nanoparticles). These fluids are engineered colloidal suspensions of nanoparticles in a base fluid. The presented work tries to discover the possibilities of augmenting the recently developed concept of nanofluids and study its effectiveness as potential working fluids for efficient heat transfer in the CTPT. The experimental setup of Closed Two Phase Thermosyphon was developed with two different nanofluids, Al2O3/water and water for different concentrations of $0.1 \%, 0.3 \%$ and $0.5 \%$ and the fill volume ratios used in CTPT were $10 \%, 20 \%$ and $30 \%$ respectively. The temperature range used for the experimentation was $30 \mathrm{oC}$ to $95 \mathrm{oC}$. Thermal analysis for different parameter has been carried out and the 
optimized solution has been provided for the given problem.

\section{APPLICATION OF NANOFLUIDS IN CTPT}

\section{Closed Two Phase Thermosyphon}

"Natural convection refers to the process wherein heat transferred to a fluid, raises its temperature and reduces its density, giving rise to buoyant forces that lift the fluid (due to density difference) and transport the absorbed heat to some other location where it can be removed". Natural convection occurs in a similar manner in two-phase systems. Here, the application of the liquid phase produces a low-density vapour that is free to rise through the liquid and condense at some other location. In either case, continuous circulation of the heat transfer fluid is maintained." The fig. 1 shows the CTPT indicating its main functional units.
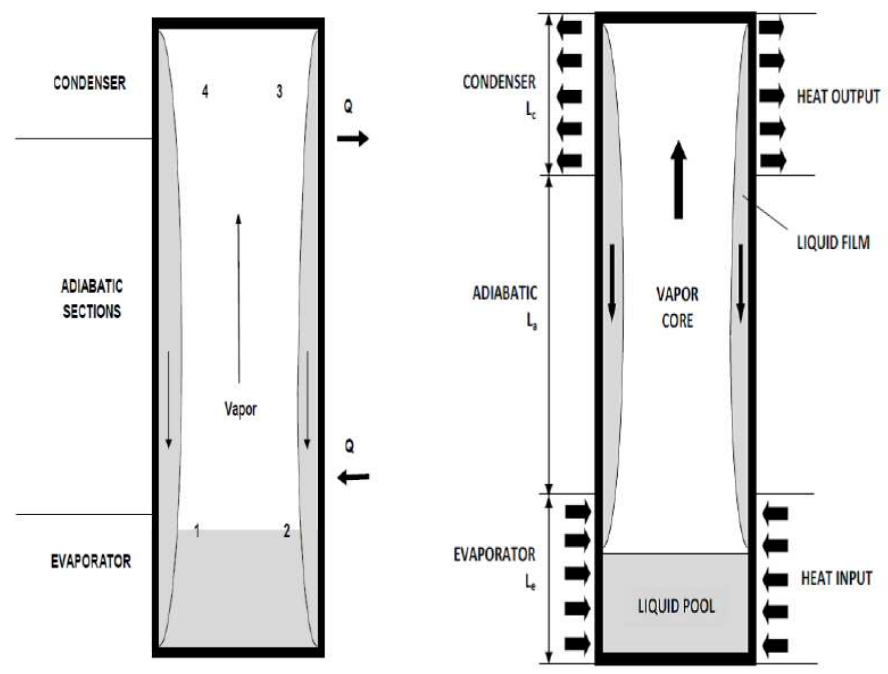

Figure 1: Conventional Closed Two Phase Thermosyphon (CTPT).

\section{Nanofluids}

The CTPT using conventional working fluids e.g water, ammonia, methanol, acitone etc. gives moderate performance and unable to surve the purpose of higher rate of heat flux at lower temperature difference. Hence the need of alternate working fluid arised and nanno flids are looked as the potential option sfor the future heat transfer devices. As metals are having higher thermal conductivity, so when they are added as nanoparticles to the conventional fluid as base fluids, it is observed that the themal conductivity of the nanofluid increases enormously. When this nanofluids are used in CTPT as working fluids then it forms a effective augumentation which leads towards the higher heat transfer artes at lower temperature difference.

There are various parameters which affects the heat transfer coefficient os the system. The parameters like nanoparticle concentration, fill ratio and heat inputs are having enrrmous effect on the themal performance of the CTPT using nanofluids.

This paper discusses the experimental method where all these parameters are varied and its effect on the themal performance of the system is determined. 


\section{WORKING FLUID INVENTRY}

For calculating the working fluid fill volume the fluid properties of the water is taken at the highest operating temperature (80 0C). The standard fluid properties are as follows:

$\mathrm{hfg}=2308.9 \mathrm{~kJ} / \mathrm{kg}, \rho_{1}=971.82 \mathrm{~kg} / \mathrm{m}^{3}, \mu_{1}=0.3515 \times 10^{-3} \mathrm{~N} . \mathrm{s} / \mathrm{m}^{2}, \mathrm{~g}=9.81 \mathrm{~m} / \mathrm{s}^{2}, \mathrm{Qc}=0.720 \mathrm{kw}, \mathrm{Di}=0.0224 \mathrm{~m}, \mathrm{Le}$ $=0.400 \mathrm{~m}, \mathrm{La}=0.200 \mathrm{~m}, \mathrm{Lc}=0.400 \mathrm{~m}$

The minimum working fluid volume for circular section geometry wickless heat pipe is calculated by using the following equation:

$$
\begin{aligned}
& V_{m}=\left[\frac{4}{5}-(0.400+0.400)+0.02\right] *\left[\frac{6 * 0.720 * 0.3515 * 10^{-3} *(\pi * 0.0224)^{2}}{(971.82)^{2} * 9.81 * 2308.9}\right] \\
& V_{m}=6.31 * 10^{-6} \mathrm{~m}^{3}=6.34 \mathrm{cc}
\end{aligned}
$$

It is a common practice to include a slight excess of working fluid over and above that of minimum amount of quantity of fluid because $80 \%$ of the volume of liquid is in phase transformation and at least $20 \%$ of the liquid is required to retain inside the evaporator to avoid the dry out. In order to calculate the quantity of the return of the liquid from the condenser section, the volume of the return liquid was calculated. From the classical Nusselt theory for film condensation on vertical surface, the local condensate mass flow rate and thickness inside a wickless heat pipe are given by

$$
\begin{aligned}
& \delta_{L_{c}}=\left[\frac{4 k_{1} \mu_{1}\left(T_{w \theta}-T_{w c}\right) L_{\theta} L_{c}}{\rho_{i}^{2} q h_{f q}\left(L_{c}{ }^{\frac{1}{4}}{ }^{\left.\frac{1}{6}\right)}\right.}\right. \\
& \delta_{L_{c}}=\left[\frac{4 * 0.669 * 0.3515 * 10^{-3} * 10 * 0.40 * 0.40 \frac{1}{4}}{971.82^{2} * 9.81 * 2308.9 * 0.8}\right] \\
& \delta_{l_{c}}=0.5445 * 10^{-3} \mathrm{~m}=0.5445 \mathrm{~mm}
\end{aligned}
$$

The local condensate mass flow rate is given by

$$
\begin{aligned}
& \dot{m}_{c}=\frac{\pi D_{i}^{\prime} \rho_{1}^{2} g \delta_{L C}{ }^{3}}{3 \mu_{1}} \\
& \dot{m}_{c}=\frac{\pi * 0.0224 * 971.82^{2} * 9.81 *\left(0.5445 * 10^{-3}\right)^{3}}{3 * 0.3515 * 10^{-3}} \\
& \dot{m}_{c}=0.009976 \frac{\mathrm{kg}}{\mathrm{s}}
\end{aligned}
$$

Therefore the volume of the return of the liquid from the condenser section is given by

$$
\begin{aligned}
& \text { Volume of the liquid, } V_{L C}=\frac{m c}{\rho} \\
& V_{l c}=0.000997 \frac{0.000997}{971.82}=1.0259 * 10^{-6} \mathrm{~m}^{3}=1.0259 \mathrm{cc}
\end{aligned}
$$


So the total volume of liquid quantity can be calculated as $20 \%$ of minimum liquid quantity should be retained in evaporator and $15 \%$ in the return of liquid from condenser section.

$$
\begin{aligned}
& \mathrm{Vt}=\mathrm{Vm}+20 \% \mathrm{Vm}+\mathrm{Vlc} \\
& \mathrm{Vt}=6.31+1.27+1.0259=8.5979 \mathrm{cc} \approx 9 \mathrm{cc}
\end{aligned}
$$

For CTPT the total working fluid volume was taken as $9 \mathrm{cc}$ (min). In order to evaluate the performance CTPT over the circular geometry wickless heat pipe the fill volumes and vacuum level (4Torr) was kept same for all wickless heat pipes. In order to study the effect of fill volume to take care of higher heat input at evaporator on the performance of wickless heat pipe, the heat pipes were charged with $16 \mathrm{cc}, 32 \mathrm{cc}, 48 \mathrm{cc}$, fill volume, having fill volume ratio (F.R) as $10 \%$, $20 \%$ and $30 \%$ of total evaporator volume(157.6cc) respectively.

\section{EXPERIMENTAL METHOD}

An experimental set up for studying the performance of wickless heat pipe has been designed as shown in Fig. 2 The test rig has the following features and facilities:

Wickless heat pipe under test, Band Heaters for evaporator section, Voltmeter and Ammeter for power input measurement, Variac for power control, Provision for measuring temperature rise of condenser coolant, Provision for tilting CTPT, Constant level water tank for maintain the condenser coolant flow Constant, K- type sensors for wall temperature measurement along the wickless heat pipe, Digital Temperature Indicator for recording the temperature from the different locations of CTPT using thermocouples.

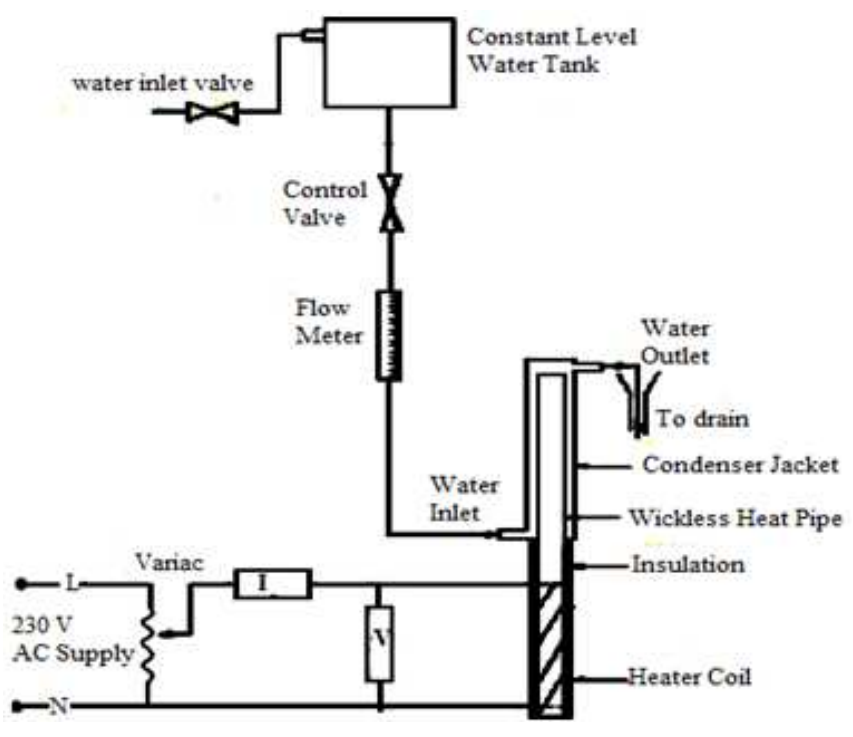

Figure 2: Schematic of Experimental Set Up.

\section{RESULTS AND DISCUSSION}

Experimentation involved distinct testing of three thermosyphon having fill ratios as 10\%, 20\% and 30\% respectively for inclinations of $30^{\circ}, 60^{\circ}$ and $90^{\circ}$ of CTPT subsequently. Voltage was varied in such a way that the heat input obtained was in steps of $200 \mathrm{~W}, 400 \mathrm{~W}$ and $600 \mathrm{~W}$ respectively and corresponding temperature readings were noted as shown by temperature indicator. The readings were taken for different heat inputs and inclination angles. The CTPT under test, as mentioned were, manufactured by using different working fluids. The working fluids used for required CTPT were two 
different nanofluids i.e. Al2O3/Water and $\mathrm{CuO} /$ Water for different concentrations of nanoparticles. Nanofluids were prepared for different concentrations of $0.1,0.3$ and 0.5 respectively and used as working fluids in the CTPT for different combinations. In addition to that CTPT having only water as working fluid were also manufactured for different fill ratios as per the previously used ratios, so that the comparison in the performance analysis of the three different sets of CTPT could be possible. Following CTPT of two types were used for testing purpose for different input variables

- $\quad$ CTPT- Distilled Water Based.

- CTPT- Al2O3/Water- Nanofluid Based.

\section{Temperature Distribution for Vertically Oriented CTPT for Different Concentrations, Fill Ratios and Heat Inputs}

Fig.3 shows the variation of temperature along CTPT for water and A12O3/Water nanofluid as a working fluid at $200 \mathrm{~W}$. The results indicate that as the concentration of nanoparticles increases, the wall temperature increases. The rise in temperature is higher for $32 \mathrm{cc}$ pipe compared to $16 \mathrm{cc}$ and $48 \mathrm{cc}$ i.e. $20 \%$ fill volume pipe performs better than the remaining two pipes .For water pipe also the trend is same i.e. it shows highest temperature of $63^{\circ} \mathrm{C}$ for $20 \%$ fill volume at $0.3 \%$ concentration. The temperature Increases from $10 \%$ fill volume to $20 \%$ fill volume and the slightly decreases for $30 \%$ fill volumes. The same can be said about the \% concentration of nanoparticles i.e. temperature increases as the concentration increases and for the $0.5 \%$ concentration it shows slight decrease in temperature. The temperatures are on the lowest sides for higher fill volumes and highest concentration for CTPT having Al2O3/Water nanofluid as a working fluid. The results for the CTPT having water as working fluid is also seen following the same trend except it performs slightly better at $30 \%$ fill volume as compared to former case.

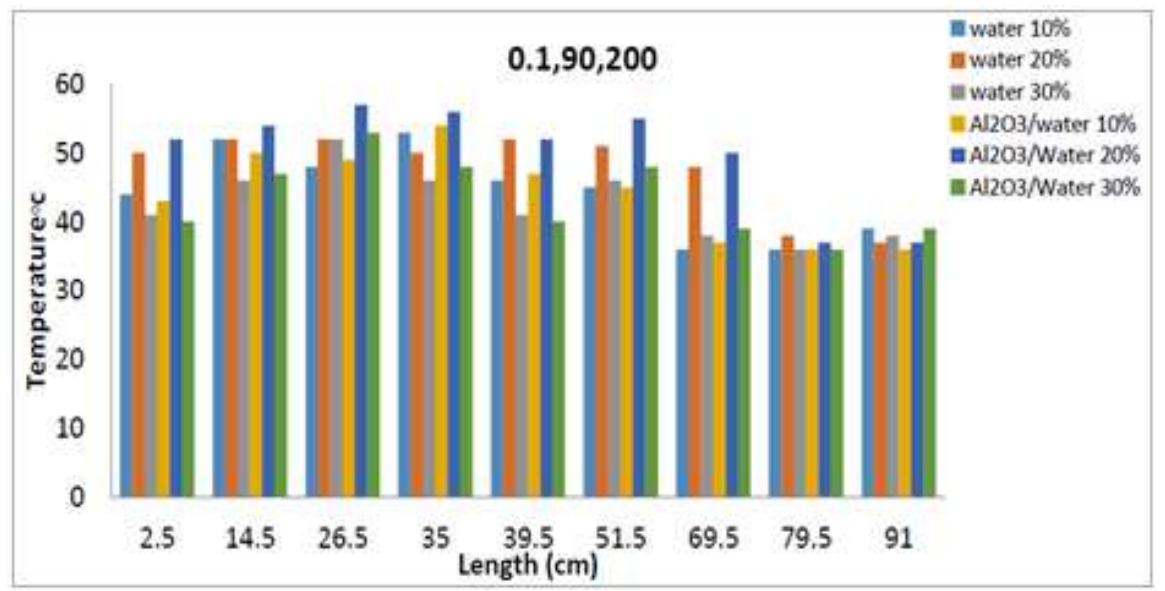

Figure 3: Temperature Distribution along the Outer Wall Surface at $200 \mathrm{~W}$ and $0.1 \%$ Concentration.

The temperature increases from $10 \%$ fill volume to $20 \%$ fill volume and the slightly decreases for $30 \%$ fill volumes. The same can be said about the \% concentration of nanoparticles i.e. temperature increases as the concentration increases and for the $0.5 \%$ concentration it shows slight decrease in temperature. The temperatures are on the lowest sides for higher fill volumes and highest concentration for CTPT having A12O3/Water nanofluid as a working fluid. The results for the CTPT having water as working fluid is also seen following the same trend except it performs slightly better at $30 \%$ fill volume as compared to former case. It is clearly observed that the temperatures recorded with nanofluid CTPT are on the higher sides as compared to the water pipe for all the cases. 


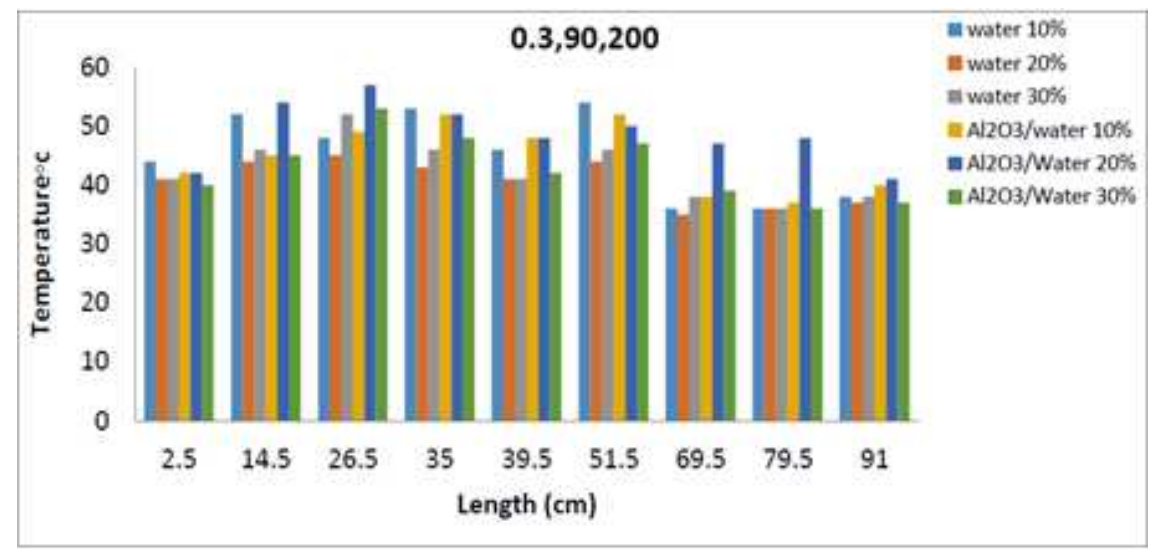

Figure 4: Effect of Heat Input of 200W on Temperature Distribution along the Outer Wall at $0.3 \%$ Concentration.

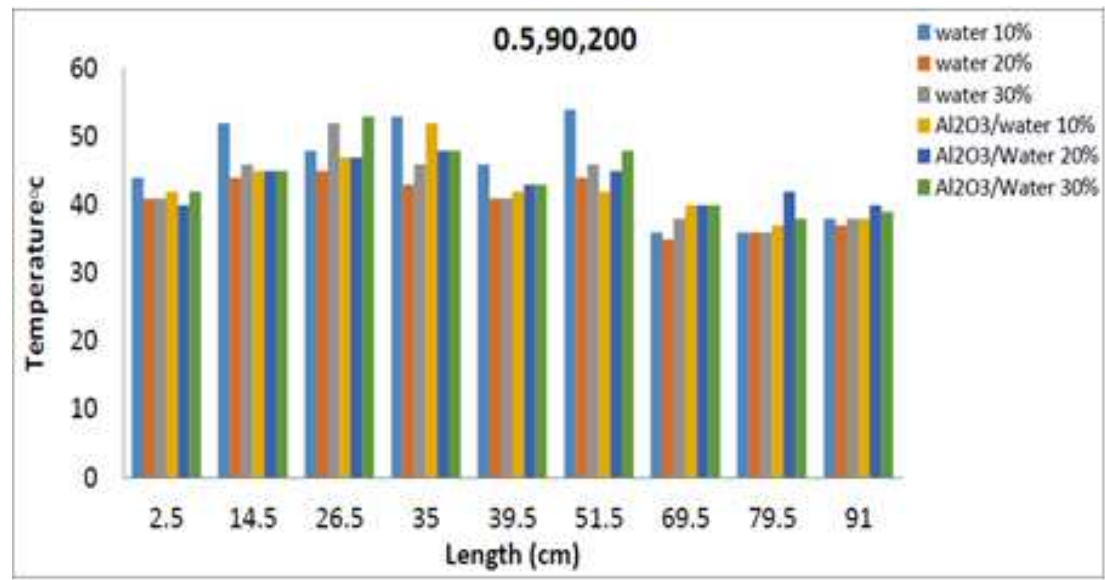

Figure 5: Temperature Distribution along the Outer Wall Surface at $200 \mathrm{~W}$ and 0.5\% Concentration.

In adiabatic section the temperature varies almost isothermal for all fill volumes. The temperature reached minimum value at the bottom part of the condenser section and increased slightly at the top part of the condenser section. Fig. 4 and Fig. 5 show the temperature distribution for heat input of $200 \mathrm{~W}$ and $0.3 \%$ and $0.5 \%$ concentration of nanoparticles. The trend shown by the results is same for the concentration of $0.1 \%$ except the wickless heat pipes with nanofluids performs better for higher concentration compared to water pipes whereas water pipes shows the higher range of temperature for lower fill volumes.

\section{Effect of Heat Pipe Input on Temperature Distribution along the Outer Wall Surface}

It is evident from the obtained results from Fig.6, Fig. 7 and Fig. 8 that the average temperature of both CTPT having water and $\mathrm{Al} 2 \mathrm{O} 3 / \mathrm{Water}$ nanofluid as working fluids increase as the heat input increase from $200 \mathrm{~W}$ to $600 \mathrm{~W}$. The percentage rise in temperature is higher at the evaporator section as compared to the condenser section. The rise in temperature is highest for $600 \mathrm{~W}$ heat input up to $85 \mathrm{oC}$. The temperature rise is highest for $400 \mathrm{~W}$ heat input at $0.3 \%$ concentration for $\mathrm{Al} 2 \mathrm{O} 3 /$ Water nanofluid CTPT with respect to the $20 \%$ fill volume ratio. 


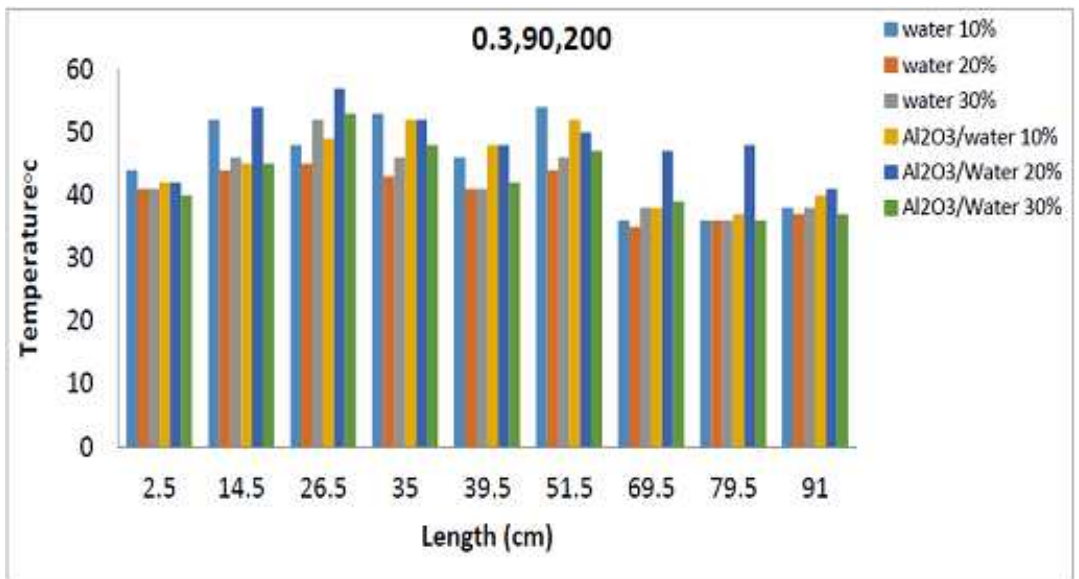

Figure 6: Effect of Heat Input of $200 \mathrm{~W}$ on Temperature Distribution along the Outer Wall at $0.3 \%$ Concentration.

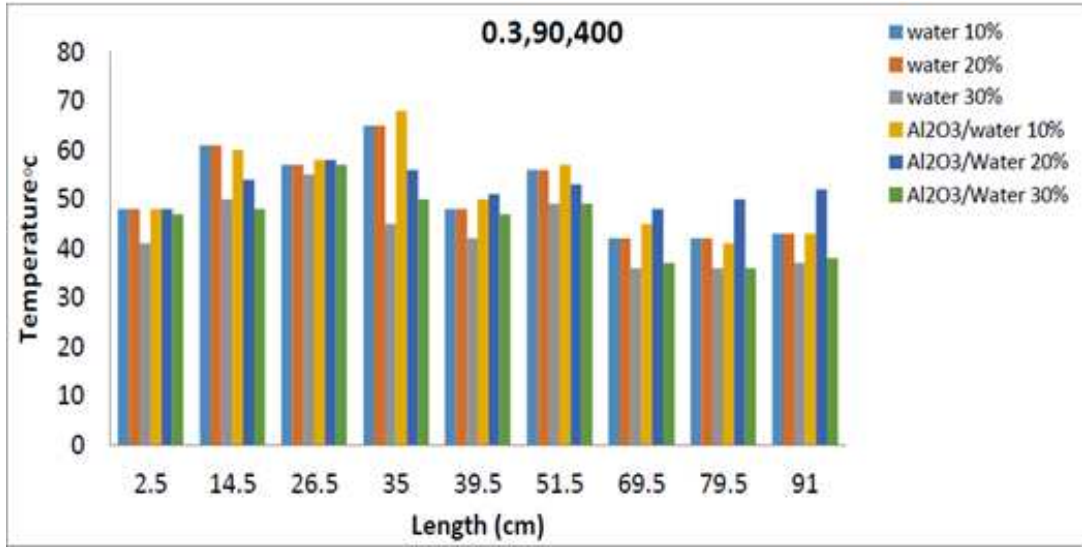

Figure 7: Effect of Heat Input of 400W on Temperature Distribution along the Outer Wall at $0.3 \%$ Concentration.

For highest fill volume, the rise is slightly lower even though the heat input is highest i.e. 600W. The average rise in temperature is $10 \%$ to $15 \%$ higher in case of CTPT with nanofluid as working fluid compared to the CTPT working on water. For the same case for the comparison between water pipes and nanofluid pipes (CuO/water nanofluid) with the case that is being discussed, it is observed that the average rise in temperature at all the three sections i.e. evaporator, adiabatic and condenser section is around $8 \%$ to $10 \%$ more than the former case.

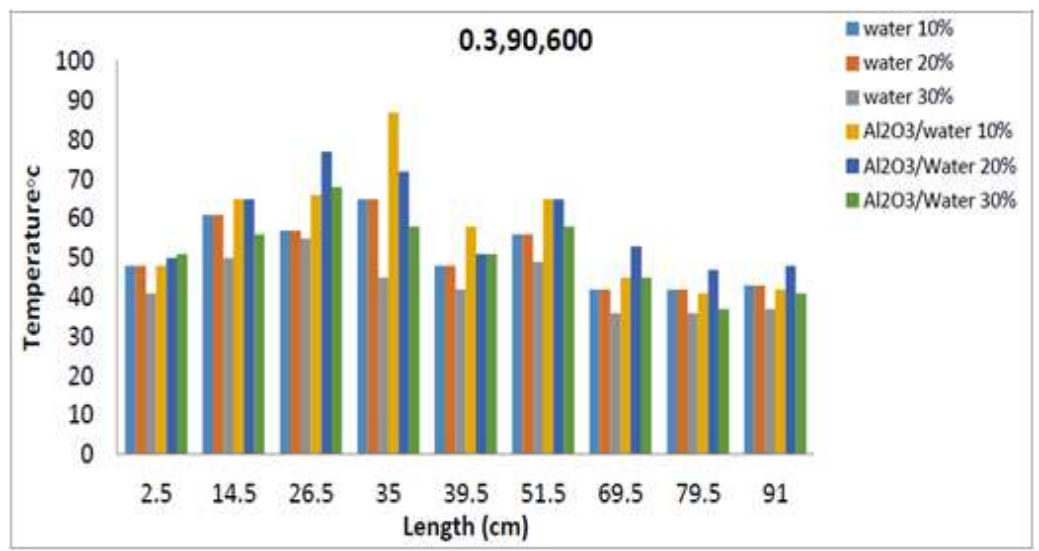

Figure 8: Effect of Heat Input of $600 \mathrm{~W}$ on Temperature Distribution along the Outside Wall at $0.3 \%$ Concentration. 


\section{CONCLUSIONS}

From experimental investigation for the performance of CTPT with different concentrations, heat input, fill charge, inclination angle and working fluids, it is concluded that:

- The increase in the thermal conductivity of $\mathrm{Al} 2 \mathrm{O} 3 /$ Water nanofluid is $1.35 \%$ for $0.1 \%$ volume at room temperature and $2.5 \%$ for $0.1 \%$ volume of nanoparticles at $95 \circ \mathrm{C}$.

- The increase in the thermal conductivity of $\mathrm{Al} 2 \mathrm{O} 3 /$ Water nanofluid is $4.32 \%$ for $0.5 \%$ volume at room temperature and $6.3 \%$ for $0.5 \%$ volume of nanoparticles at $95 \mathrm{oC}$.

- It is observed that the thermal conductivity of the nanofluid increases continuously for higher temperatures and concentrations of nanoparticles, although the rise is non- linear and declines for higher values.

- The temperature distribution along the wall surface of evaporator section for nanofluid based CTPT was higher than that of water based CTPT.

- The liquid film in the evaporator was dried out; when fill charge is less and heat inputs are higher.

- The $16 \mathrm{cc}$ combined nanofluid and water based closed thermosyphon pipes were showing comparatively higher wall temperatures for higher heat inputs of $400 \mathrm{~W}$ and $600 \mathrm{~W}$.

\section{REFERENCES}

1. Dong Hyun Cho, Kyu-il Han, Influence of the inclination angle and liquid charge ratio on the condensation in closed twophase thermosyphons with axial internal low fins, KSME International Journal 17 (3) (2003) 422-428.

2. Karthikeyan M., Vaidyanathan S., Sivaraman B., Thermal performance of a two phase closed thermosyphon using aqueous solution, International Journal ofEngineering Science and Technology 2 (5) (2010) 913-918.

3. Kumar, Sandeep, and Satbir Singh Sehgal. "Efficient Solar Collector Material and Working." International Journal 7.4 (2017): 29-38.

4. Behrooz Mirzaei Ziapour, Hadi Shaker, Heat transfer characteristics of a two phase closed thermosyphon using different working fluids, Heat Mass Transfer (2010) 46:307-314.

5. Devdatta P. Kulkarni, Ravikanth S. Vajjha, Debendra K. Das, Daniel Oliva, Application of Aluminium oxide nanofluids in diesel electric generator as jacket water coolant, Applied Thermal Engineering 28 (2008) 1774-1781.

6. Arunachala, U. C., et al. "Stability improvement in natural circulation loop using tesla valve-an experimental investigation." International Journal of Mechanical and Production Engineering Research and Development, 9 (6), 1324 (2019).

7. Mohamed I. Hassan, Ismail A. Alzarooni, Youssef Shatilla, The effect of water based nanofluid incorporating Al2O3 nanoparticles on heat pipe performance, Energy Procedia 75 (2015) 3201-3206.

8. Ramesh K Rathod, Suhas C Kongre, Shriramshastri Chavali, "Characterization of Nanofluids Using Experimental and Analytical Methods for Different Concentrations", Nano Trends: A Journal of Nanotechnology and Its Applications Volume 1 , Issue, ISSN: $0973418 X$ (Online)

9. Sameer Khandekar, Yogesh M. Joshi, Balkrishna Mehta. Thermal performance of closed two-phase thermosyphon using nanofluids, International Journal of Thermal Sciences 47 (2008) 659 - 667. 
10. Jabbar, Ahmed Abdulhussein, et al. "Design and Analysis of Gas Turbine Rotor Blade Using finite Element Method." International Journal of Mechanical and Production, ISSN (P) (2014): 2249-6890.

11. Jian Qu, Hui-ying Wu, Ping Cheng, Thermal performance of an oscillating heat pipe with Al2O3- Water nanofluids, International Communications in Heat and Mass Transfer 37 (2010) 111-115.

12. Ehsan Firouzfar, Mohammad Soltanieh, S. Hossien Noie, S. Hassan Saidi, Energy saving in HVAC systems using nanofluid, Applied Thermal Engineering 31 (2011) 1543-1545.

13. Zhen-hua Liu, Xue-fei Yang, Guo-san Wang, Guang-liang Guo, Influence of carbon nanotube suspension on the thermal performance of a miniature thermosyphon, International Journal of Heat and Mass Transfer 53 (2010) 1914-1920.

14. Benziger, B., P. Anu Nair, and P. Balakrishnan. "Review paper on thermoelectric air conditioner using peltier modules." IJME 4.

15. Gabriela Huminic, Angel Huminic, Experimental and numerical investigations of the thermal performances of wickless heat pipes using nanofluids, Termotehnica 1/2013.

16. M.G. Mousa, Effect of nanofluid concentration on the performance of circular heat pipe, Ain Shams Engineering Journal (2011) 2, 63-69.

17. Paisarn Naphon, Pichai Assadamongkol, Experimental investigation of titanium nanofluids on the heat pipe thermal efficiency, International Communications in Heat and Mass Transfer 35 (2008) 316 - 1319. 

